\title{
MUSIM KERTAS LIUR (MUDAH DAN SIMPLE KERAJINAN TAS TALI KUR)
}

\author{
Nopiar Prahmawati, Dwi Nurcahyanti, Tita Alfatiaga Irdianiza. \\ n.prahmawati@yahoo.com \\ Mahasiswa Fakultas Keguruan dan Ilmu Pendidikan
}

\begin{abstract}
ABSTRAK
MUSIM KERTAS LIUR (Mudah dan Simple Kerajinan Tangan Tas Tali Kur) adalah tas yang terbuat dari rangkaian tali, kemudian dianyam dengan keterampilan dan buatan tangan sendiri. Tas tali kur adalah tas yang kuat mampu bertahan selama bertahun - tahun, bahannya kuat yang menjadikan tas lebih awet dan tahan lama. Sehingga pada saat itulah sudah semakin banyak yang menggemari nya, dan membuat orang yang memakai tas tali kur terlihat lebih cantik dan menawan. Hingga di berbagai toko tas dan accessories yang telah menjual produk tas dari tali dengan berbagai macam bentuk dan model yang menarik dan unik yang cocok untuk wanita. Sudah banyak orang yang membelinya untuk dirinya sendiri, dan ada juga yang membelinya untuk di berikan kepada orang yang dia sayanginya. Tujuan dari pembuatan MUSIM KERTAS LIUR ini adalah untuk meningkatkan kreativitas ibu - ibu PKK dan menambahkan ilmu tentang kegiatan yang dilakukan dengan memenuhi keinginan akan barang - barang unik sehingga produk ini dapat diminati banyak kalangan dan juga warga di daerah Leuwisadeng. Dalam kegiatan ini , metode yang kami gunakan adalah menawarkan kreativitas dengan mengeksplor berbagai macam bentuk baru dengan ragam warna dan pola yang simple dan unik agar menarik dan dapat disesuaikan dengan kebutuhan konsumen.
\end{abstract}

Kata Kunci: Kreativitas, Kewirausahaan, MUSIM KERTAS LIUR (Mudah dan Simple Kerajinan Tas Tali Kur).

\section{PENDAHULUAN}

\section{Latar Belakang}

Seni anyam sudah ada sejak dahulu kala, hingga sekarangpun masih akrab dalam kehidupan masyarakat. Bahkan hampir di seluruh nusantara terdapat home industri pengrajin barang anyam-anyaman. Maka bisa dikatakan seni anyam termasuk kategori warisan budaya yang harus dilestarikan.

Salah satu seni menganyam adalah merajut dengan bahan dasar tali kur. Mempunyai keahlian dalam merajut dengan tali kur saat ini, dapat dijadikan modal sebagai pendapatan tambahan dan dapat berkembang menjai bisnis tetap. Bisnis rajut talikur, memang sudah berkembang sejak lama. Hingga kini, bisnis rajut talikur masih memiliki lahan pasar yang cukup luas. Tentu saja dengan kualitas jempolan dan inovasi yang tidak pasaran.

Yang menarik dalam proses pembuatan tas atau perlengkapan lain menggunakan talikur ini adalah kebanyakan proses pembuatannya yang $100 \%$ handmade atau hasil buatan tangan. Sehingga hasilnya dapat benarbenar detail bagus dan menawan. Apalagi dengan perpaduan warna yang serasi, 
tentu mata pasar akan tertarik untuk memperjual belikannya.

Produk yang dibuat dengan menggunakan talikur sendiri sampai saat ini sudah sangat beragam. Mulai dari tas tangan, tas selempang, tas punggung, tas pinggang, dompet, tempat ponsel, tas laptop, hiasan rumah, topi, bahkan sepatu. Tentunya yang disukai pasar adalah yang tidak hanya berbahan talikur, melainkan dikombinasi dengan berbagai bahan. Seperti mutiara, flanel, dan masing banyak lagi kombinasi yang lainnya sehingga produk talikur tidak terkesan kaku.

\section{Gambaran Umum Produk}

Usaha yang bernama MUSIM KERTAS LIUR ini dibuat karena kami merasa sudah banyak masyarakat yang meninggalkan hal-hal yang kurang menarik, kebutuhan masyarakat yang makin meningkat membuat kami berinisiatif untuk membuat suatu inovasi pada tas yang pasti digunakan oleh banyak orang untuk menghias penampilan, membawa barang-barang dan sebagainya. Pembuatan usaha kerajinan tas ini didasari oleh pengamatan yang dilakukan disekitar, dimana masyarakat menyukai hal-hal yang unik. Peluang bisnis yang sangat menjanjikan khususnya tas tali kur yang dapat dipesan sesuai keinginan pembeli.

Ide muncul dari pengamatan yang dilakukan di tempat-tempat seperti rumah, perkumpulan ibu-ibu dan tempattempat lainnya yang biasanya mencirikan keunikan. Dengan ditambah ide kreatif produk kerajinan tas ini dapat membantu masyarakat yang membutuhkan inovasi pada tas untuk melengkapi penampilan seseorang pada jaman modern saat ini. a. Produk
Produk ini menggunakan bahanbahan sebagai berikut :

a. Tali kur

b. Gunting

c. Lem Tembak

d. Benang

e. Jarum Pentul

f. Lilin

g. Dan lain sebagainya

Adapun produk ini dapat di design sesuai dengan keinginan pembeli.

\section{Peluang Pasar}

Pencarian pasar kerajinan tas tali kur dapat dilakukan dengan penjualan online yaitu penjualan yang menggunakan media sosial seperti penjualan tidak langsung yaitu Instagram, Tokopedia, dan Bukalapak, serta pada penjualan secara langsung seperti menawarkan langsung kepada perkumpulan ibu-ibu arisan dll.

Pemasaran yang akan dilakukan bekerja sama dengan Galeri Kerajinan di Daerah Leuwisadeng yang telah berpengalaman dalam pemasaran kerajinan tas tali kur. Sehingga pada program PKM-K di rencanakan untuk mengikuti Pameran Produk Kerajinan yang diikuti oleh para perajin di daerah Leuwisadeng. Keikutsertaan dalam pameran kerajinan ini akan membawa dampak peningkatan jaringan pasar diantara penyelenggara dengan para perajin di Leuwisadeng serta memperkenalkan produk kerajinan tas tali kur tersebut.

\section{Gambaran Strategi Pemasaran}

a. Segmen Pasar, yang dituju adalah :

1. Kelompok masyarakat berpenghasilan menengah keatas - Kelompok Ibu-ibu PKK , arisan dll b. Target Utama 
2. Kelompok masyarakat yang ingin mempunyai model tas unik seperti tas tali kur.

3. Perusahaan yang akan memberi cinderamata bagi, tamu, rekan usaha atau karyawan berprestasi.

\section{METODE PENGABDIAN}

Metode yang digunakan dalam pelaksanaan kegiatan usaha ini adalah berdasarkan input, proses dan output produksi sebagai berikut :

\section{Input pra produksi}

a. Sebelum kita melakukan tahap produksi, kami melakukan survey pasar sebagai langkah awal, dan merencanakan inovasi. Tujuan kami melakukan survey ini adalah untuk mengetahui kondisi pasar, minat konsumen.

b. Setelah itu yang akan kami lakukan setelah survey pasar adalah study kelayakan terhadap usaha yang akan kami jalankan. Studi kelayakan ini dilakukan untuk mengetahui apakah kegiatan ini memiliki prospek yang menguntungkan dan memiliki prospek jangka panjang.

c. Tahap terakhir adalah pemilihan bahan dan penyediaan tempat serta sarana dan prasarana untuk menunjang proses produksi

\section{Proses (produksi)}

a. Pertama, menyediakan alat dan bahan

b. Kedua, Ambillah dua utas tali kur sepanjang 2 meter. Ambil bagian tengah tali sebagai patokan dan lipat menjadi dua. Anggap saja baris tali diibaratkan nomor 1-4 dari kiri. b. Positioning, Konsumen melihat produk kerajinan tas tali kur produksi tim kami ini sebagai produk yang kreatif, inovatif, unik, lain dari yang lain dan harganya yang sangat terjangkau

c. Ambil tali no. 4 dan tarik ke belakang.

d. Letakkan tali no.1 di belakang tali no.4.

e. Ambil tali no.1 dan kunci dengan memasukkan ke lubang depan (lubang hasil dari tali no.3 dan no.4)

f. Tarik tali no.1 ke arah kiri, gunakan tali no.4 untuk mengunci dengan melipatnya ke kanan dan memasukkannya ke lubang belakang.

g. Tarik kuat dan jadilah satu kepala sebagai dasar. Buatlah dasar kepala dengan jumlah yang genap agar tas imbang kiri kanan. Semakin besar tas yang ingin dibuat maka sebanyak pula dasar kepala yang diperlukan.

h. Kemudian untuk menyambung kepala menjadi satu rangkaian, caranya persis sama hanya saja dua kelapa yang dirangkai dijadikan dua utas untuk bagian kanan dan dua utas untuk bagian kiri pada dasar kepala yang berada.

i. Selanjutnya, buatlah model rangkaian bawah tas agar nanti tas yang dibuat lebih bagus dan juga menarik.

\section{Output}

Output dari produksi yang kami buat ini adalah berbagai macam bentuk kerajinan tas tali kur untuk dijual dan dikirim kepada konsumen yang memesan. 


\section{REALISASI PROGRAM}

\section{Anggaran Biaya}

\begin{tabular}{|c|l|c|c|c|c|}
\hline No & \multicolumn{1}{|c|}{ Uraian Biaya } & $\begin{array}{c}\text { Unit / } \\
\text { Quantity }\end{array}$ & $\begin{array}{c}\text { Satuan } \\
\text { Harga }\end{array}$ & Jumlah & $\begin{array}{c}\text { Cakupan } \\
\text { (\%) }\end{array}$ \\
\hline 1. & $\begin{array}{l}\text { Peralatan Penunjang } \\
(\text { Maks 10\%) }\end{array}$ & & & 727.000 & $6 \%$ \\
\hline 2. & $\begin{array}{l}\text { Bahan habis pakai } \\
(7081 \%)\end{array}$ & & & 10.123 .000 & $81 \%$ \\
\hline 3. & Perjalanan (Maks 10\%) & & & 1.050 .000 & $8 \%$ \\
\hline 4. & Lain - lain (Maks 5\%) & & & 600.000 & $\mathbf{5 \%}$ \\
\hline & Total Pengeluaran & & & $\mathbf{1 2 . 5 0 0 . 0 0 0}$ & $\mathbf{1 0 0 \%}$ \\
\hline
\end{tabular}

Jadwal Kegiatan

\begin{tabular}{|c|c|c|c|c|c|c|c|c|c|c|c|c|c|c|c|c|c|c|c|c|c|}
\hline \multirow{2}{*}{ No } & \multirow{2}{*}{ Kegiatan } & \multicolumn{4}{|c|}{ Bulan 1} & \multicolumn{4}{|c|}{ Bulan 2} & \multicolumn{4}{|c|}{ Bulan 3} & \multicolumn{4}{|c|}{ Bulan 4} & \multicolumn{4}{|c|}{ Bulan 5} \\
\hline & & 1 & 2 & 3 & 4 & 1 & 2 & 3 & 4 & 1 & 2 & 3 & 4 & 1 & 2 & 3 & 4 & 1 & 2 & 3 & 4 \\
\hline 1 & Persiapan & & & & & & & & & & & & & & & & & & & & \\
\hline 2 & $\begin{array}{l}\text { Pembuatan } \\
\text { Proposal }\end{array}$ & & & & & & & & & & & & & & & & & & & & \\
\hline 3 & $\begin{array}{l}\text { Proses } \\
\text { Administrasi }\end{array}$ & & & & & & & & & & & & & & & & & & & & \\
\hline 4 & $\begin{array}{l}\text { Proses } \\
\text { Produksi }\end{array}$ & & & & & & & & & & & & & & & & & & & & \\
\hline 5 & $\begin{array}{l}\text { Monitoring } \\
\text { dan } \\
\text { Pemasaran }\end{array}$ & & & & & & & & & & & & & & & & & & & & \\
\hline 6 & $\begin{array}{l}\text { Pembuatan } \\
\text { Laporan } \\
\text { Akhir }\end{array}$ & & & & & & & & & & & & & & & & & & & & \\
\hline
\end{tabular}




\section{KESIMPULAN}

\section{Tujuan}

Berdasarkan rumusan masalah diatas, dapat diketahui tujuan untuk membuat proposal ini, yaitu :

a. Untuk mengtahui minat masyarakat tentang barang-barang unik.

b. Untuk mengetahui bagaimana caranya memasarkan produk kerajinan tas tali kur yang benar.

c. Untuk mengetahui sasaran pasar untuk menggunakan produk kerajinan tas tali kur sebagai pelengkap penampilan.

\section{Luaran Yang Diharapkan}

a. Luaran yang dihasilkan dari usaha ini adalah kerjainan tas yang terbuat dari bahan tali kur yang dibentuk sesuai design pembeli. b. Kerajinan tas tali kur ini dapat menjadi solusi bagi masyarakat luas khususnya wanita untuk melengkapi penampilan dengan menggunakan kerajinan tas tali kur sesuai dengan keinginannya sendiri.

\section{Manfaat dan Kegunaan}

Produk luaran yang dihasilkan mempunyai manfaat dan kegunaan sebagai berikut:

a. Sebagai wadah untuk membawa barang-barang yang diperlukan.

b. Sebagai pelengkap penampilan bagi wanita yang sangat bervariasi dilihat dari latar belakang keunikannya.

c. Meningkatkan inovasi dalam menemukan hasil karya yang dapat digunakan sebagai peluang usaha yang menjanjikan. 